\title{
Endoscopic ultrasonography-guided drainage of a rectal mucocele after total colectomy for Crohn's disease
}
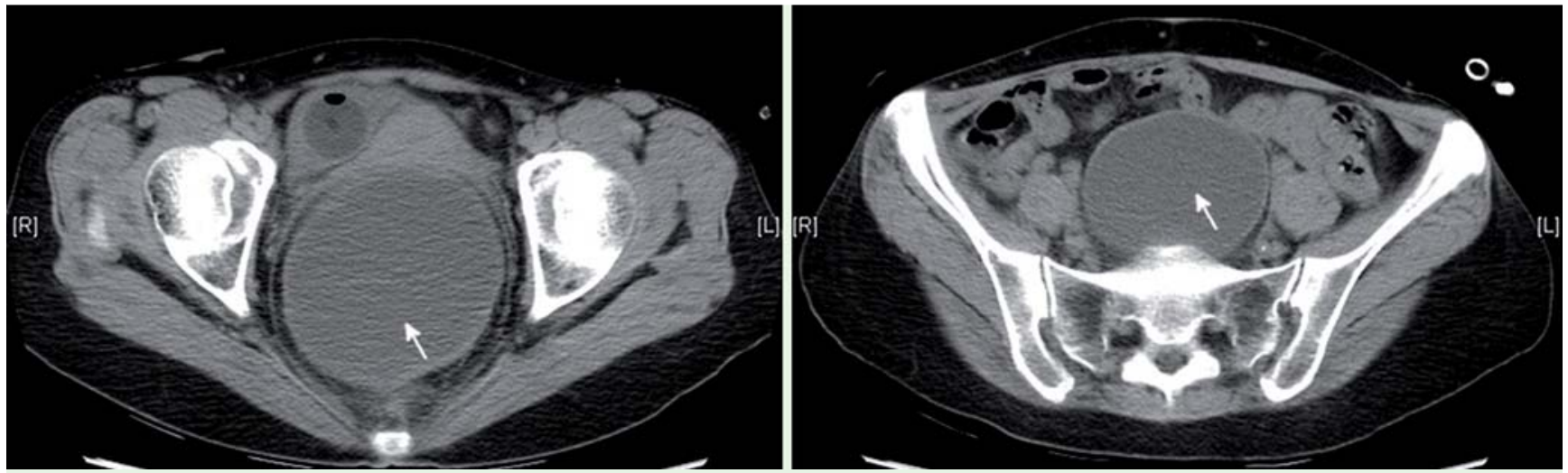

Fig. 1 Computed tomography showing a grossly distended rectal stump (arrow head).

A 40-year-old woman was admitted with acute urinary retention and failed to wean off the Foley catheter. She had a known history of Crohn's disease and 5 years previously had undergone total colectomy and end ileostomy as treatment for massive gastrointestinal bleeding due to pancolitis. Computed tomography showed a grossly distended rectal stump up to $15 \times$ $9 \mathrm{~cm}$ in size ( Fig.1). Sigmoidoscopy showed a blind-ended stump $5 \mathrm{~cm}$ from the anal verge. The overall features were compatible with a large rectal stump mucocele.

The patient was scheduled for endoscopic ultrasound (EUS)-guided transrectal drainage. The rectal mucocele was punctured by a 19-gauge needle (Echo-19; Cook Medical Inc., Bloomington, Indiana, USA) using a curvilinear echoendoscope (GF-UTC 260; Olympus, Tokyo, Japan) introduced via the anus. A 0.025-inch guide wire (Visiglide; Olympus) was inserted and looped around the mucocele ( $\bullet$ Fig. 2). The track of the guide wire was dilated to $8 \mathrm{~mm}$ in size using a controlled radial expansion balloon (Boston Scientific, Natick, Massachusetts, USA). Another guide wire was inserted into the mucocele and two plastic stents were placed (10 Fr $\times$ $5 \mathrm{~cm}$ and $7 \mathrm{Fr} \times 4 \mathrm{~cm}$ ) ( Fig. 3). There was good drainage of large amounts of clear viscous fluid. Follow-up computed tomography 1 month later showed complete resolution of the mucocele ( $\bullet$ Fig. 4 ). The patient was able to void following the procedure.

Rectal mucoceles are a rare entity and occur as a result of distal stenosis in the

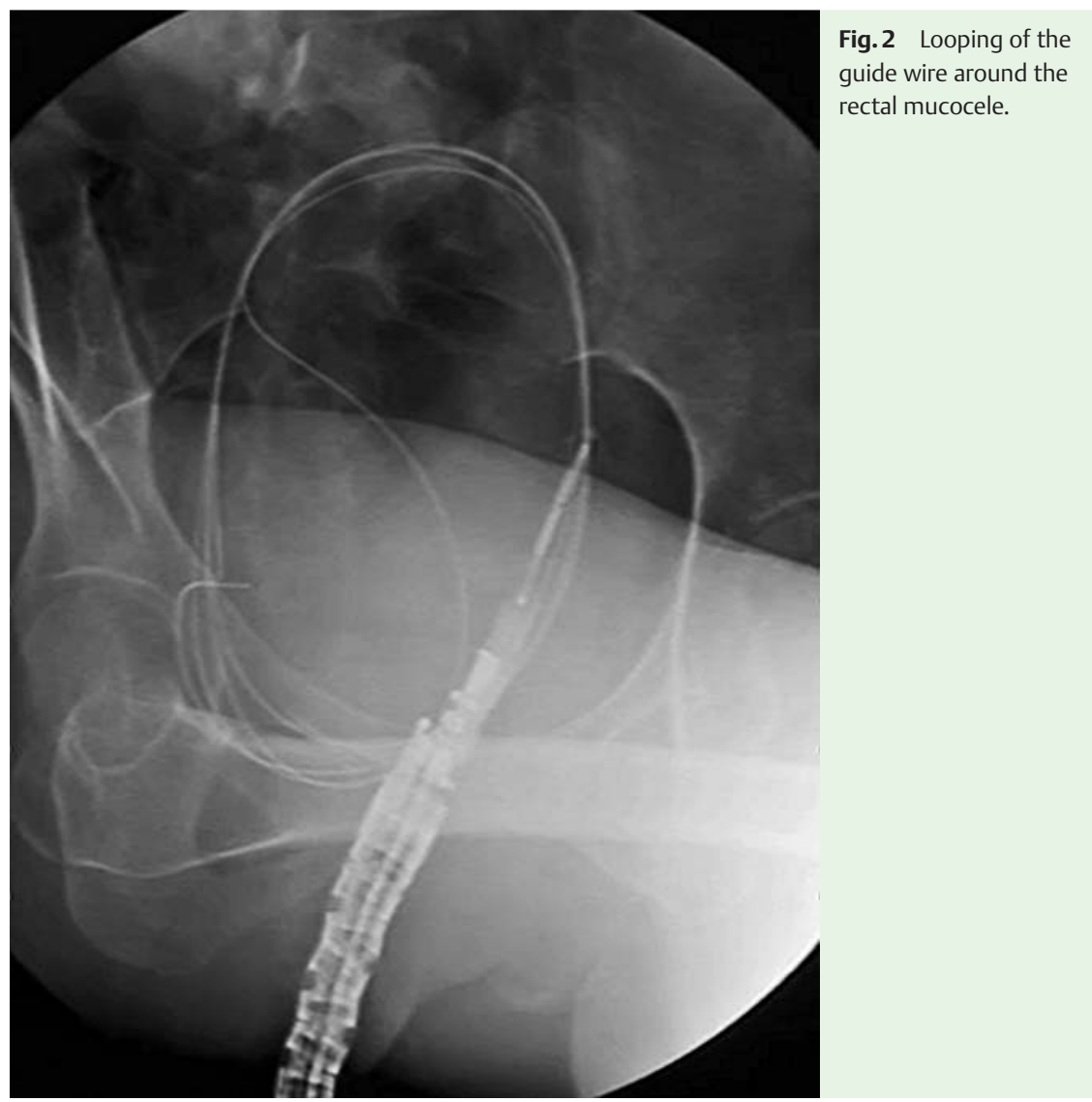

rectal stump after colectomy and end colostomy $[1,2]$. They are more commonly seen in patients who have undergone surgery for complications of inflammatory bowel diseases. These mucoceles can grow slowly over a prolonged period and can reach large sizes. They can then exert pressure upon surrounding organs and can compress the bladder and ureter. Tra- ditional treatment involves percutaneous drainage or surgical resection [3]. To our knowledge, the current case is the only report in which EUS was used for therapy by guiding internal drainage.

\section{Endoscopy_UCTN_Code_TTT_1AQ_2AJ}

Competing interests: None 




Fig. 3 Placement of two plastic stents for drainage of the mucocele.
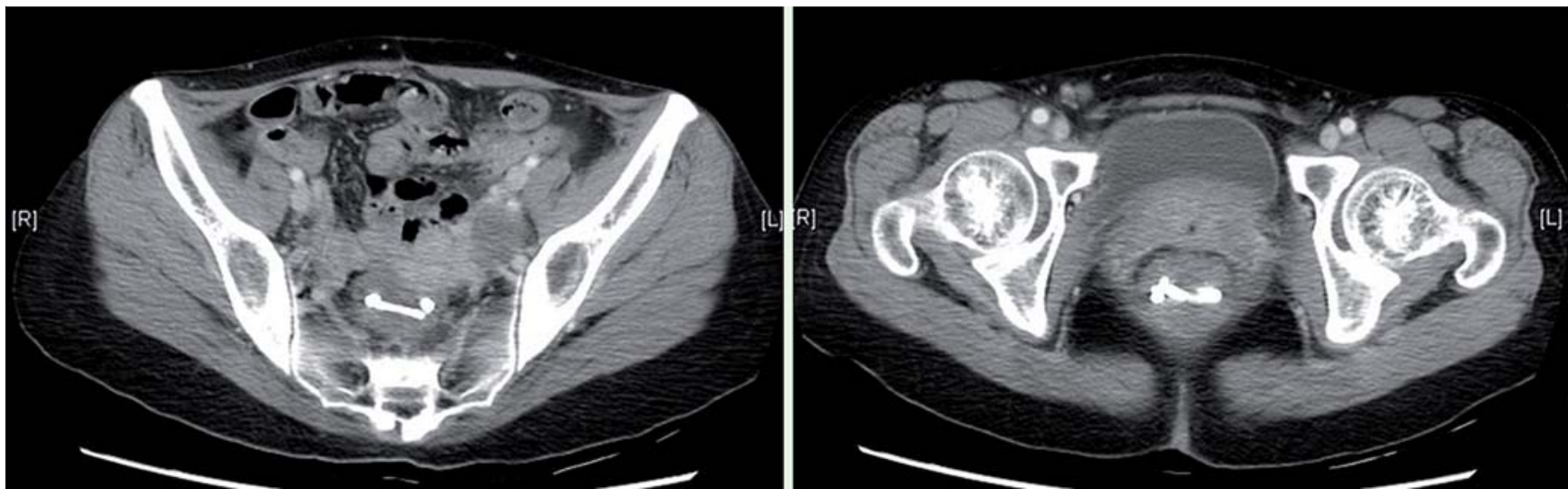

Fig.4 Follow-up computed tomography 1 month later showed complete resolution of the mucocele.

A. Y. B. Teoh' ${ }^{1}$, J. F. Y. Lee',

\section{C. N. Chong' ${ }^{1}$ R. S. Y. Tang ${ }^{2}$}

${ }^{1}$ Department of Surgery, Prince of Wales Hospital, The Chinese University of Hong Kong, Hong Kong SAR, China

${ }^{2}$ Institute of Digestive Disease, The Chinese University of Hong Kong, Hong Kong SAR, China

\section{References}

1 Witte JT, Harms BA. Giant colonic mucocele after diversion colostomy for ulcerative colitis. Surgery 1989; 106: 571-574

2 Creagh MF, Chan TYK. Rectal mucocele following Hartmann's procedure. Clin Radiol 1991; 43: 358-359

3 Subhas G, Balaraman S, Mittal VK et al. Extraluminal rectal mucocele resulting from bowel sequestration at the anastomotic site after sigmoidectomy. Am Surg 2010; 76: $107-108$
Bibliography

DOI http://dx.doi.org/

10.1055/s-0033-1344415

Endoscopy 2013; 45: E252-E253

(c) Georg Thieme Verlag KG

Stuttgart · New York

ISSN 0013-726X

\section{Corresponding author}

\section{A. Y. B. Teoh, MD, FRCSEd (Gen)}

Department of Surgery

Prince of Wales Hospital

The Chinese University of Hong Kong

Shatin

Hong Kong

Fax: $+852-26377974$

anthonyteoh@surgery.cuhk.edu.hk 